\title{
BMJ open Public support for tobacco control policy extensions in Western Australia: a cross- sectional study
}

\author{
Michael Rosenberg, ${ }^{1}$ Simone Pettigrew, ${ }^{1}$ Lisa Wood, ${ }^{2}$ Renee Ferguson, ${ }^{1}$ \\ Stephen Houghton ${ }^{3}$
}

To cite: Rosenberg M, Pettigrew S, Wood L, et al. Public support for tobacco control policy extensions in Western Australia:

a cross-sectional study. BMJ Open 2012;2:e000784.

doi:10.1136/

bmjopen-2011-000784

- Prepublication history for this paper is available online. To view this file please visit the journal online (http://dx. doi.org/10.1136/ bmjopen-2011-000784).

Received 20 December 2011 Accepted 9 February 2012

This final article is available for use under the terms of the Creative Commons Attribution Non-Commercial 2.0 Licence; see http://bmjopen.bmj.com

${ }^{1}$ Health Promotion Evaluation Unit, School of Sport Science, Exercise and Health, The University of Western Australia, Perth, Australia ${ }^{2}$ Centre for the Built Environment and Health, School of Population Health, The University of Western Australia, Perth, Australia ${ }^{3}$ Centre for Child and Adolescent Related Disorders, The University of Western Australia, Perth, Australia

Correspondence to Dr Professor Simone Pettigrew; simone. pettigrew@uwa.edu.au

\section{ABSTRACT \\ Objectives: Policy makers seeking to introduce new tobacco control measures need to anticipate community support to assist them in planning appropriate implementation strategies. This study assessed community support for plain packaging and smoking bans in outdoor locations in Australia. \\ Design: Analytical cross-sectional survey. \\ Setting and participants: 2005 Western Australian adults participated in a computer-assisted telephone interview. Random household telephone numbers were used to obtain a representative sample.}

Outcome measures: Support for plain packaging of cigarettes and smoking bans at outdoor venues by demographic characteristics.

Results: Around half of the survey respondents supported plain packaging and almost a further quarter reported being neutral on the issue. Only one in three smokers disagreed with the introduction of a plain packaging policy. A majority of respondents supported smoking bans at five of the six nominated venues, with support being strongest among those with children under the age of 15 years. The venues with the highest levels of support were those where smoke-free policies had already been voluntarily introduced by the venue managers, where children were most likely to be in attendance, and that were more limited in size.

Conclusions: The study results demonstrate community support for new tobacco control policies. This evidence can be used by public policy makers in their deliberations relating to the introduction of more extensive tobacco control regulations.

\section{INTRODUCTION}

Tobacco control policies to date have encompassed various elements including cessation assistance, taxation, restrictions on tobacco advertising and removal of point of sale displays, tobacco packaging regulations and designation of non-smoking areas. ${ }^{1}$ Most tobacco control policies have considerable public support across varying countries and among both smokers and non-smokers. ${ }^{2-12}$ As the evidence base relating to the harms associated with secondhand smoke grows and

\section{ARTICLE SUMMARY}

\section{Article focus}

- This study assessed public support in Australia for progressive tobacco control policies in the form of plain packaging of cigarettes and smoking bans in outdoor locations.

- The results can inform policy makers' efforts to develop and implement new tobacco control policies.

\section{Key messages}

- The majority of respondents were supportive or neutral towards the introduction of plain packaging. Around a quarter of all respondents and a third of smokers disagreed with the proposed policy.

- A majority of respondents supported smoking bans at a broad range of venues including parks, zoos and community events. Support was strongest among parents and for smaller outdoor venues.

- The results indicate that new regulations relating to plain packaging and smoking bans in outdoor locations are likely to receive considerable public support.

Strengths and limitations of this study

- The large sample $(n=2005)$ and use of random digit dialling provide robust results relating to the likely responses of Western Australians to new tobacco control policies.

- Further research is needed in other countries to assess the extent to which the results reflect prevailing community views elsewhere.

tobacco consumption becomes increasingly de-normalised in many countries, some governments are stepping up their efforts to further discourage smoking at a population level. ${ }^{13}{ }^{14}$ Two areas of possible tobacco control policy extension include plain packaging of cigarettes and smoking bans in outdoor locations. ${ }^{1} 214$

In line with work demonstrating that the visual characteristics of cigarette packages convey important information to consumers and influence their perceptions of the 
healthiness and desirability of the product, ${ }^{15}$ recent research indicates that plain packaging may reduce demand for cigarettes. In Australia, Wakefield and colleagues ${ }^{16}{ }^{17}$ demonstrated that as branding symbolism is reduced on packages, associations of the types of people who would use the product and assessments of the appeal of the product become progressively more negative. Similarly, research by Hoek et $a l^{18}$ with young adult smokers in New Zealand indicated that the brand information displayed on cigarette packages can be important for identity construction and communication for this age group, and hence that the minimisation of this information and the inclusion of more prominent health warnings can reduce the attraction of the product. Attitudinal research conducted in the USA, ${ }^{19}$ Canada, ${ }^{20}$ the $\mathrm{UK}^{15}{ }^{21}$ and France $^{22}$ has reached the same general conclusions.

In a world first, legislation has been passed in Australia that requires plain packaging to be phased in on all cigarette packages during 2012. ${ }^{23} 24$ There has been considerable support for plain packaging among key stakeholders, including public health advocates and the three primary political parties. ${ }^{1}{ }^{25}$ However, anecdotal evidence suggests that the issue is more contentious among the general public, an outcome that is at least partly attributed to concerted efforts by the tobacco industry to incite public opposition to the change. ${ }^{25}$ Research is therefore necessary to gauge levels of support for plain packaging to assist governments in planning appropriate implementation strategies.

Restrictions on smoking in public places have been found to be effective in terms of achieving compliance among smokers and reducing exposure to secondhand smoke. ${ }^{4}$ They can also contribute to the prevention of smoking uptake among children and young people by reshaping the perceived social acceptability of smoking. ${ }^{26}$ The ability of smoke-free policies to normalise non-smoking is evident in the dramatic increases in support for such policies that have occurred in numerous countries post-implementation. ${ }^{427-29}$ Of note is that many of these policies have been introduced on the basis of research evidence despite only minority support pre-implementation.

While numerous countries have implemented smoking bans in workplaces, restaurants and bars, ${ }^{27} 30$ and in some cases the outdoor areas adjacent to these locations, ${ }^{14}$ other outdoor locations remain mostly unregulated. To date, there appears to have been little research on the extent of support for bans in outdoor locations characterised by open spaces that are not directly adjacent to buildings. In their review of the few studies that have explored this issue, Thomson and colleagues $^{31}$ noted that there are typically high levels of community support but that further research is needed to more comprehensively assess the extent of support for such bans and how this may vary in different contexts. ${ }^{31}$

While high levels of community support are not a prerequisite for successful policy implementation due to the normalisation outcomes noted above, they are likely to be of value in facilitating policies through the relevant legislative processes and minimising the costs associated with community consultation and education. Evidence relating to levels of support for new tobacco control policies is useful for informing governments of (1) the extent to which legislative changes are aligned with community attitudes and (2) any variations in attitudes among different stakeholder groups. This information can assist in ensuring that new policies are effectively communicated to enhance acceptance and compliance. ${ }^{2}{ }^{32}$ Awareness of public attitudes is particularly important in the context of sophisticated lobbying and public relations activities by the tobacco industry ${ }^{33}$ and the potential for media coverage to influence support for tobacco control policies. ${ }^{34} 35$

To this end, the present study investigated public support for plain packaging of cigarettes and smoking bans at a range of outdoor venues. Australia, the context of the study, is acknowledged to be one of the world leaders in tobacco control interventions. ${ }^{6} 7{ }^{30}$ Attitudes to smoke-free policies have become more positive over the last decade, ${ }^{14}$ and the proportion of the adult population classified as current daily smokers has decreased to $19 \%$ nationally and $12 \%$ in Western Australia. ${ }^{36} 37$ These outcomes have been attributed to ongoing public education campaigns and other tobacco control strategies implemented since the 1970s. ${ }^{14} 3839$ The purpose of the study was to investigate whether the population is amenable to further policy extensions.

The study was funded by the Western Australian Health Promotion Foundation. Clearance was obtained from the UWA Human Ethics Committee and no competing interests were declared.

\section{METHOD}

\section{Sample and survey design}

Data for this study were collected via a household telephone survey in November 2010. Respondents were residents of Western Australia aged 18-69 years. Telephone numbers were randomly selected from an electronic household telephone directory. Although the directory included only landlines (ie, mobile phone numbers are not listed), the rate of landline ownership in Australia has remained high over the last decade at around $88 \% .^{40}$ The adult in the house with the next birthday was invited to participate in the survey. Up to 10 call backs were made to each household to maximise the response rate, resulting in a response rate of $60 \%$ among eligible households. The final sample comprised 2005 respondents, $66 \%$ of whom resided in the Perth Metropolitan area and the remainder in country areas. To adjust for any differences from the general population, the sample was weighted to the age and location distribution of the Western Australian population aged 16-69 years according to 2006 census data. ${ }^{41}$

The survey instrument comprised a range of questions relating to lifestyle and attitudes to smoking. One item 
Table 1 Venues and venue attributes

\begin{tabular}{|c|c|c|c|c|}
\hline \multirow[b]{2}{*}{ Venue } & \multicolumn{4}{|c|}{ Venue attributes } \\
\hline & Land size & $\begin{array}{l}\text { Family or general } \\
\text { population focus }\end{array}$ & Smoke-free policy status & Frequency of event \\
\hline Perth Zoo & 41 acres & Family & $\begin{array}{l}\text { Smoking only permitted in } \\
\text { dedicated smoking areas }\end{array}$ & Continual \\
\hline $\begin{array}{l}\text { South Perth Foreshore } \\
\text { Family Zone }\end{array}$ & 30 acres & Family & Total smoking ban & Annual \\
\hline Perth Royal Show & 75 acres & Family & Total smoking ban & Annual \\
\hline Adventure World theme park & 660 acres & Family & Total smoking ban & Summer only \\
\hline Kings Park & 1003 acres & General & No policy & Continual \\
\hline Rottnest Island & 31179 acres & General & No policy & Continual \\
\hline
\end{tabular}

asked respondents whether they agreed, disagreed or had no feelings about the introduction of plain packaging on cigarettes. The Australian government had announced its intention to introduce plain packaging in April $2010,{ }^{25}$ and it was likely that many respondents were aware of this at the time of the survey. Other survey items asked respondents whether they supported, did not support or had no feelings either way about smoke-free policies in six outdoor venues: the Perth Zoo, the South Perth Foreshore Family Zone (a riverfront venue for music festivals), the Perth Royal Show (an annual agricultural event), Adventure World (a theme park), Kings Park (a national park located adjacent to the city centre) and Rottnest Island (a holiday resort island located $20 \mathrm{~km}$ from the mainland). The purposefully selected venues represented a wide range of locations, including some that had elected to be smoke fre ${ }^{i}$ and others that had no smoking policies at the time of data collection. Some of the venues were family oriented, while others attracted the general population. Some were permanent fixtures, while others were annual or seasonal events. Almost all the venues, with the exception of the Royal Show, had an estimated $90 \%$ or more open space within the venue boundaries. Table 1 provides a description of each of the venues included in the study.

Data analysis comprised descriptive statistics to ascertain attitudes towards the two proposed tobacco control policies. The $\chi^{2}$ statistic was used to determine significant association between policy support and participant characteristics (age, gender, smoking status and having a child under 15 years of age). Multinomial logistic regression models were used to generate ORs for agreement/no agreement with the proposed policies, adjusting for respondents who 'had no feelings either way' and the participant characteristics explored in the descriptive analyses. All statistical analyses were performed using SPSS V.19.0.

\footnotetext{
'These venues had recently received sponsorship funding from the Western Australian Health Promotion Foundation to facilitate the introduction of smoke-free policies.
}

\section{RESULTS}

The sample comprised 1016 men $(50.7 \%)$ and 989 women $(49.3 \%)$, with $29.3 \%(\mathrm{n}=588)$ aged $16-29$ years, $42.0 \%(\mathrm{n}=842)$ aged $30-49$ years and $28.7 \%(\mathrm{n}=575)$ aged 50-69 years. Almost two-thirds of respondents $(63.5 \% ; \mathrm{n}=1273)$ had no children under 15 years of age, and around half $(53.5 \% ; \mathrm{n}=1073)$ had completed postsecondary education. The sample comprised $12.3 \%$ $(\mathrm{n}=344)$ current smokers, $22.6 \% \quad(\mathrm{n}=473)$ ex-smokers and $59 \%(\mathrm{n}=1189)$ who had never smoked. A significantly higher proportion of men than women were current smokers $(21.9 \%$ vs $12.3 \%$; $\mathrm{p}<0.00)$.

Table 2 shows the overall and subgroup levels of support for a plain packaging policy. Around half the total sample were in agreement, a quarter disagreed and a further quarter reported that they had no feelings either way. Agreement levels were lower among smokers, with approximately a third in agreement, a quarter neutral and the remainder expressing disagreement. Non-smokers (including ex-smokers) were 2.7 times (95\% CI 2.0 to 3.6) more likely than smokers to agree, while smokers were 2.6 times (95\% CI 1.9 to 3.6 ) more likely to have no feelings either way. Men were more likely than women to agree with plain packaging (53.3\% vs $47.8 \%$; OR $1.4,95 \%$ CI 1.1 to 1.7 ) and less likely to have no feelings either way $(21.3 \%$ vs $24.4 \%$; OR 0.9 , $95 \%$ CI 0.7 to 1.2 ). Compared with respondents aged 16-29 years (42.0\%), respondents aged 50-69 years (55.1\%) were 2.0 (95\% CI 1.5 to 2.7 ) times more likely to agree with the introduction of plain packaging.

As can be seen in table 3, support for smoking bans was strong for four of the six specified outdoor locations. Those who had never smoked and those with children under 15 years of age demonstrated the highest levels of support for smoking bans at all six venues. Of note is that support was strong among smokers for some venues, especially the South Perth Foreshore and the Zoo.

Table 4 provides the ORs for the variables of gender, age, parental status and smoking status. Respondents' smoking status was the strongest indicator of likely support, with significant and large differences in the ORs of ex-smokers and non-smokers compared with smokers for each of the venues. Independent of smoking 


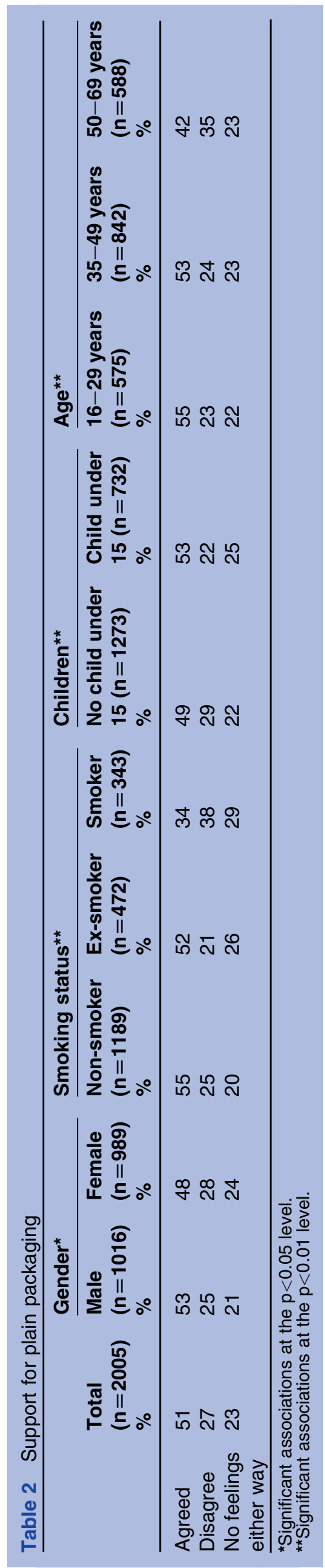

status, women were more likely than men to support the Perth Zoo, the South Perth Foreshore and the Perth Royal Show becoming smoke-free venues. Independent of smoking status, gender had little impact on support for smoke-free venues, with the exception of women who were 1.3 times more likely than men to support the Zoo being a non-smoking venue. Similarly, age was observed to have little independent effect on support for smokefree venues, with the exceptions of Adventure World, where a smoking ban was supported significantly more by respondents aged $30+$ years, and Kings Park, where respondents aged $30-49$ years were less likely to support a smoking ban.

Respondents with children under 15 years of age were more likely than other respondents to support smoking bans at the South Perth Foreshore, the Royal Show and Adventure World. Women with children under 15 years of age were 1.6 (95\% CI 1.08 to 2.49) times more likely than other women to support smoking bans at the Zoo. No significant independent relationship was observed for parental status and support for the introduction of bans at Kings Park, the Zoo or the South Perth Foreshore.

Along with respondent characteristics, it is likely that venue attributes influenced support levels. Respondents were more supportive of smoke-free policies for venues that already had smoking restrictions in place, were smaller in size and had a family focus. In general, as venue size increased and the target population attending the venues became more representative of the general public, support weakened.

\section{DISCUSSION}

The present study investigated public attitudes to potential tobacco control policy extensions, namely plain packaging requirements and smoking bans at outdoor venues. In terms of community support for plain packaging, approximately half of the survey respondents supported the initiative and almost a quarter were neutral. This suggests that there is unlikely to be a substantial public backlash when plain packaging is introduced in Australia. Of note is that only one in three current smokers, who constitute $12 \%$ of the Western Australian adult population, disagreed with the policy. In the light of a primary aim of plain packaging policy being to discourage new adopters, ${ }^{14}{ }^{42}$ this may reflect high levels of regret for smoking initiation among current smokers. ${ }^{43} 44$

As governments increasingly legislate against smoking in workplaces and other indoor locations, extension to outdoor contexts is the next frontier. Smoking bans in outdoor settings may have multiple benefits in terms of reducing non-smokers' exposure to secondhand smoke, encouraging smokers to reduce their intake or quit and avoiding instances of adults modelling and normalising tobacco consumption to children. ${ }^{45}$ However, there is a need to better understand community support for such policy extensions to optimise implementation and 
Table 3 Support for outdoor smoking bans by venue and respondent characteristics

\begin{tabular}{|c|c|c|c|c|c|c|c|c|}
\hline Venue & $\begin{array}{l}\text { Total } \\
(n=2005) \\
\%\end{array}$ & $\begin{array}{l}\text { Male } \\
(n=1016) \\
\%\end{array}$ & $\begin{array}{l}\text { Female } \\
(n=989) \\
\%\end{array}$ & $\begin{array}{l}\text { Non-smoker } \\
(n=1189) \\
\%\end{array}$ & $\begin{array}{l}\text { Ex-smoker } \\
(n=472) \\
\%\end{array}$ & $\begin{array}{l}\text { Smoker } \\
(n=343) \\
\%\end{array}$ & $\begin{array}{l}\text { No child } \\
\text { under } 15 \\
(n=1273) \\
\%\end{array}$ & $\begin{array}{l}\text { Child under } \\
15(n=732) \\
\%\end{array}$ \\
\hline Perth Zoo* $† \neq$ & 85 & 81 & 89 & 90 & 84 & 68 & 83 & 88 \\
\hline $\begin{array}{l}\text { South Perth Foreshore } \\
\text { Family Zone* } \dagger \neq\end{array}$ & 82 & 80 & 84 & 85 & 82 & 72 & 80 & 85 \\
\hline Perth Royal Show & 80 & 77 & 83 & 96 & 78 & 60 & 77 & 84 \\
\hline $\begin{array}{l}\text { Adventure World } \\
\text { theme park }{ }^{*} \dagger \neq\end{array}$ & 77 & 74 & 81 & 83 & 77 & 58 & 75 & 81 \\
\hline Kings Park† & 52 & 52 & 54 & 62 & 49 & 26 & 52 & 53 \\
\hline Rottnest Island $†$ & 43 & 42 & 44 & 51 & 40 & 19 & 42 & 45 \\
\hline
\end{tabular}

compliance. Reflecting the findings of limited previous work in this area, ${ }^{31}$ the results of the present study show majority support for smoking bans at five of the six nominated venues. The one exception was an island resort that is large in acreage and patronised by both local residents and tourists. The tendency for support to be highest among venues that already have voluntary smoking bans in place is aligned with previous research suggesting that support for bans increases post-implementation. ${ }^{27} 2830$

Past research has found women to be generally more supportive of smoking policies than men. ${ }^{6}{ }^{32}$ In the present study, women tended to be more supportive of smoking bans in outdoor venues, but men were more supportive of plain packaging. The reasons for women's lower support for plain packaging are not clear and would require further research to understand whether this outcome relates to weaker beliefs about the potential effectiveness of this approach or stronger involvement with brands per se. ${ }^{46}$ More advanced age has been associated with greater support for smoking policies elsewhere, ${ }^{32}$ and this was found to be the case for plain packaging and smoking bans at some of the nominated venues but not all. It thus appears that demographic attributes may have varying relationships to support levels in different national contexts and that country-specific research needs to be undertaken to assess likely reactions to policy changes among different population segments.

Other areas of possible future research include (1) investigation of public support for plain packaging legislation once it has been fully implemented, (2) analysis of venue management and community support for voluntary versus mandatory smoke-free policies in outdoor areas and (3) assessment of the impact of media coverage of proposed tobacco control policies on levels of community support. In addition, further research analysing associations between smoke-free policies and children's normative beliefs about smoking (such as their estimates of peer or community prevalence and views on social acceptability) would be a valuable contribution to youth smoking prevention research.

Despite some variations in support for plain packaging and outdoor smoking bans by demographic characteristics, the overall levels of support for these policies suggest that it would not be necessary to differentially accommodate age and gender in communications strategies designed to educate the community about their introduction and implementation. However, the large variations in support by smoking status indicate

Table 4 Support for smoking bans at nominated outdoor venues

\begin{tabular}{|c|c|c|c|c|c|c|}
\hline & $\begin{array}{l}\text { Zoo } \\
\text { OR (95\% Cl) }\end{array}$ & $\begin{array}{l}\text { South Perth } \\
\text { OR }(95 \% \mathrm{Cl})\end{array}$ & $\begin{array}{l}\text { Royal Show } \\
\text { OR }(95 \% \mathrm{Cl})\end{array}$ & $\begin{array}{l}\text { Adventure world } \\
\text { OR }(95 \% \mathrm{Cl})\end{array}$ & $\begin{array}{l}\text { Kings Park } \\
\text { OR }(95 \% \mathrm{Cl})\end{array}$ & $\begin{array}{l}\text { Rottnest } \\
\text { OR }(95 \% \mathrm{Cl})\end{array}$ \\
\hline Male & - & - & - & - & - & - \\
\hline Female & 1.5 (1.1 to 2.1$)$ & 1.7 (1.1 to 2.5$)$ & 1.5 (1.1 to 2.0$)$ & NS & NS & NS \\
\hline $16-29$ & - & - & - & - & - & - \\
\hline $30-49$ & NS & NS & NS & 1.6 (1.1 to 2.3$)$ & 0.7 (0.6 to 1.0$)$ & NS \\
\hline $50-69$ & NS & NS & NS & 2.2 (1.5 to 3.3$)$ & NS & NS \\
\hline No child under 15 & - & - & - & - & - & - \\
\hline Child under 15 & NS & NS & 1.9 (1.4 to 2.8$)$ & 1.4 (1.0 to 1.9$)$ & NS & $1.3(1.0$ to 1.7$)$ \\
\hline Smoker & - & - & - & - & - & - \\
\hline Ex-smoker & 3.1 (2.0 to 4.4$)$ & NS & 3.3 (2.3 to 4.8$)$ & 2.4 (1.7 to 3.5$)$ & 3.0 (2.2 to 4.1$)$ & 3.2 (2.3 to 4.6$)$ \\
\hline Never smoked & 7.2 (5.0 to 10.3$)$ & 2.9 (1.8 to 4.6$)$ & 7.1 (5.1 to 9.9$)$ & 6.0 (4.3 to 8.4$)$ & 5.6 (4.2 to 7.4$)$ & 6.2 (4.6 to 8.4$)$ \\
\hline
\end{tabular}


that smokers are a specific communications audience that may require special consideration. For example, information relating to the types of outdoor venues affected by any new smoke-free policy would need to be broadly disseminated to prevent smokers from arriving at these venues without being able to prepare for abstinence during attendance.

In conclusion, the results of the present study demonstrate community support for more stringent tobacco control policies in Australia. This evidence may be of use to public policy makers in their deliberations relating to future extensions of existing regulations. Further research is needed in other countries to assess the extent to which the results reflect prevailing community views in other locations.

Contributors All authors contributed substantially to the study. MR, LW and RF conceptualised the design and implemented data collection. MR, RF, SP and $\mathrm{SH}$ were involved in data analysis and interpretation. All authors contributed to the literature review and writing of the article.

Funding Supported by Health Promotion Foundation of Western Australia. Competing interests None.

Ethics approval Ethics approval was provided by University of Western Australia Human Ethics Committee.

Provenance and peer review Not commissioned; externally peer reviewed.

Data sharing statement Other than the results presented in the paper, no additional data are available.

\section{REFERENCES}

1. Freeman B, Gartner C, Hall W, et al. Forecasting future tobacco control policy: where to next? Aust N Z J Public Health 2010;34:447-50.

2. Blake $\mathrm{KD}$, Viswanath $\mathrm{K}$, Blendon $\mathrm{RJ}$, et al. The role of tobacco-specific media exposure, knowledge, and smoking status on selected attitudes toward tobacco control. Nicotine Tob Res 2010;12:117-26.

3. Brown A, Boudreau C, Moodie C, et al. Support for removal of pointof-purchase tobacco advertising and displays: findings from the International Tobacco Control (ITC) Canada survey. Tob Control. Published Online First: 15 October 2011. doi:10.1136/tobaccocontrol2011-050153

4. Edwards R, Thomson G, Wilson N, et al. After the smoke has cleared: evaluation of the impact of a new national smoke-free law in New Zealand. Tob Control 2008;17:e2.

5. Gallus S, Rosato V, Zuccaro P, et al. Attitudes towards the extension of smoking restrictions to selected outdoor areas in Italy. Tob Control 2012;21:59-62.

6. Hitchman SC, Fong GT, Zanna MP, et al. Support and correlates of support for banning smoking in cars with children: findings from the ITC Four Country Survey. Eur J Public Health 2011;21:360-5.

7. Li Q, Hyland A, O'Connor R, et al. Support for smoke-free policies among smokers and non-smokers in six cities in China: ITC China Survey. Tob Control 2010;19(Suppl 2):i40-6.

8. Pacheco J. Trends-public opinion on smoking and anti-smoking policies. Public Opin Quart 2011;75:576-92.

9. Wong G, Pawson R, Owen L. Policy guidance on threats to legislative interventions in public health: a realist synthesis. BMC Public Health 2011;11:222.

10. Danishevski K, Gilmore A, McKee M. Public attitudes towards smoking and tobacco control policy in Russia. Tob Control 2008;17:276-83.

11. Gardner B, West R. Public support in England for raising the price of cigarettes to fund tobacco control activities. Tob Control 2010;19:331-3.

12. Wilson N, Weerasekera D, Edwards R, et al. Characteristics of smoker support for increasing a dedicated tobacco tax: national survey data from New Zealand. Nicotine Tob Res 2010;12:168-73.

13. Francis JA, Abramsohn EM, Park HY. Policy-driven tobacco control. Tob Control 2010;19(Suppl 1):i16-20.
14. Scollo M, Winstanley M. Tobacco in Australia: Facts and Issues. Melbourne: Cancer Council Victoria, 2008

15. Hammond D, Dockrell M, Arnott D, et al. Cigarette pack design and perceptions of risk among UK adults and youth. Eur J Public Health 2009;19:631-7.

16. Wakefield MA, Germain D, Durkin SJ. How does increasingly plainer cigarette packaging influence adult smokers' perceptions about brand image? An experimental study. Tob Control 2008;17: 416-21.

17. Germain D, Wakefield MA, Durkin SJ. Adolescents' perceptions of cigarette brand image: does plain packaging make a difference? $J$ Adolesc Health 2010;46:385-92.

18. Hoek J, Gendall P, Gifford H, et al. Tobacco branding, plain packaging, pictorial warnings, and symbolic consumption. Qual Health Res. Published Online First: 27 December 2011. doi:10.1177/ 1049732311431070

19. Thrasher JF, Rousu MC, Hammond D, et al. Estimating the impact of pictorial health warnings and "plain" cigarette packaging: evidence from experimental auctions among adult smokers in the United States. Health Policy 2011;102:41-8.

20. Doxey J, Hammond D. Deadly in pink: the impact of cigarette packaging among young women. Tob Control 2011;20: 353-60.

21. Moodie C, Mackintosh AM, Hastings G, et al. Young adult smokers' perceptions of plain packaging: a pilot naturalistic study. Tob Control 2011;20:367-73.

22. Gallopel-Morvan K, Moodie C, Hammond D, et al. Consumer perceptions of cigarette pack design in France: a comparison of regular, limited edition and plain packaging. Tob Control. Published Online First: 13 October 2011. doi:10.1136/tobaccocontrol2011-050079

23. Chapman S, Freeman B. From brand to bland-the demise of cigarette packaging. BMJ 2011;343:d4376.

24. Wakefield M. Welcome to cardboard country: how plain packaging could change the subjective experience of smoking. Tob Control 2011;20:321-2.

25. Freeman B. Tobacco plain packaging legislation: a content analysis of commentary posted on Australian online news. Tob Control 2011;20:361-6.

26. Smart RG, Stoduto G. Interventions by students in friends' alcohol, tobacco, and drug use. J Drug Educ 1997;27:213-22.

27. Cooper J, Borland $\mathrm{R}$, Yong $\mathrm{HH}$, et al. Compliance and support for bans on smoking in licensed venues in Australia: findings from the International tobacco control four-country survey. Aust N Z J Public Health 2010;34:379-85.

28. Fong GT, Hyland A, Borland R, et al. Reductions in tobacco smoke pollution and increases in support for smoke-free public places following the implementation of comprehensive smoke-free workplace legislation in the Republic of Ireland: findings from the ITC Ireland/UK Survey. Tob Control 2006;15(Suppl 3):iii51-8.

29. Hyland A, Hassan LM, Higbee C, et al. The impact of smokefree legislation in Scotland: results from the Scottish ITC: Scotland/UK longitudinal surveys. Eur J Public Health 2009;19:198-205.

30. Borland $\mathrm{R}$, Yong $\mathrm{HH}$, Siahpush $\mathrm{M}$, et al. Support for and reported compliance with smoke-free restaurants and bars by smokers in four countries: findings from the International Tobacco Control (ITC) Four Country Survey. Tob Control 2006;15(Suppl 3): iii34-41.

31. Thomson G, Wilson N, Edwards R. At the frontier of tobacco control: a brief review of public attitudes toward smoke-free outdoor places. Nicotine Tob Res 2009;11:584-90.

32. Doucet JM, Velicer WF, Laforge RG. Demographic differences in support for smoking policy interventions. Addict Behav 2007;32:148-57.

33. Davis RM, Wakefield M, Amos A, et al. The Hitchhiker's Guide to Tobacco Control: a global assessment of harms, remedies, and controversies. Annu Rev Public Health 2007;28. 171-94

34. Nagelhout GE, van den Putte $\mathrm{B}$, de Vries $\mathrm{H}$, et al. The influence of newspaper coverage and a media campaign on smokers' support for smoke-free bars and restaurants and on secondhand smoke harm awareness: findings from the International Tobacco Control (ITC) Netherlands Survey. Tob Control 2012;21:24-9.

35. Harris JK, Shelton SC, Moreland-Russell S, et al. Tobacco coverage in print media: the use of timing and themes by tobacco control supporters and opposition before a failed tobacco tax initiative. Tob Control 2010;19:37-43.

36. Australian Bureau of Statistics. Smoking and Risk Behaviours in Australia, 2007-08. Canberra, 2011. Catalogue No 4841.0.

37. Davis P, Joyce S. Health and Wellbeing of adults in Western Australia 2010, Overview and Trends. Perth: Department of Health, Western Australia, 2011 
38. Wood LJ, Rosenberg M, Clarkson J, et al. Encouraging young Western Australians to Be Smarter than smoking. Am J Health Promot 2009;23:403-11.

39. Mitchell J, Rosenberg M, Wood L. Adolescents with attitude...changes in views about smoking over time. Health Promot $J$ Austr 2008;19:109-12.

40. Australian Communications and Media Authority. Convergence and Communications Report 1: Australian Household Consumers' TakeUp and Use of Voice Communications Services. Canberra: Australian Communications and Media Authority, 2012.

41. Australian Bureau of Statistics. CDATA01. Canberra, ACT: Australian Bureau of Statistics, 2006.

42. Munafo MR, Roberts N, Bauld L, et al. Plain packaging increases visual attention to health warnings on cigarette packs in non-smokers and weekly smokers but not daily smokers. Addiction

2011;106:1505-10; discussion 11-12.

43. Fong GT, Hammond D, Laux FL, et al. The near-universal experience of regret among smokers in four countries: findings from the International Tobacco Control Policy Evaluation Survey. Nicotine Tob Res 2004;6(Suppl 3):S341-51.

44. Wilson N, Edwards R, Weerasekera D. High levels of smoker regret by ethnicity and socioeconomic status: national survey data. $N Z M e d$ $J$ 2009;122:99-100.

45. Thomson G, Wilson N, Edwards R, et al. Should smoking in outside public spaces be banned? Yes. BMJ 2008;11:337.

46. Fournier S. Consumers and their brands: developing relationship theory in consumer research. J Consumer Res 1998;24: $343-73$ 